American J. of Engineering and Applied Sciences 2 (1):160-164, 2009

ISSN 1941-7020

(C) 2009 Science Publications

\title{
Probabilistic Empirical Green's Function Method in Ground Motion Simulation
}

\author{
Ehsan Khojastehfar, Amir Saedi Daryan and Mohammad Amin Assareh \\ Civil Faculty, K.N. Toosi University of Technology, \\ P.O. Box 15875-4416, Tehran, Iran
}

\begin{abstract}
Problem statement: The Empirical Green's Function method is used to synthesize strong ground motion time histories.In previous simulation processes parameters were taken deterministically. Approach: In this study, the probabilistic consideration for some of these parameters was inserted to the process. For implementing this method a computer program was developed in GIS. GIS abilities for storing and processing geographic data is used to make Strong Ground motion simulation more convenient. Results: The 2003 Bam Earthquake strong ground motions were used for the simulation. Also for considering the probabilistic parameters the Logic Tree method is used. Conclusions/Recommendations: Probability distribution of peak ground acceleration and spectral acceleration are presented as the results of probabilistic simulation.
\end{abstract}

Key words: Strong ground motion simulation, probability, logic tree method, empirical green's function, GIS, process, parameter

\section{INTRODUCTION}

Strong ground motion is the main earthquake hazard and can cause a lot of loss to human assets. One of the main aims of engineering seismology is to predict the engineering ground motion time histories for a region according to seismological sources, path effects and local site effects. These time histories, then, may be used for engineering design, retrofitting the existing structures, hazard and risk management programs and developing new seismic codes and standards. Although using a lot of strong ground motion recording instruments has provided huge amount of information for recent earthquakes, but simulation process is also vital for providing a means of including specific information about the earthquake source, the wave propagation path and local site effects. Methods of ground motion simulation may be categorized into deterministic methods, stochastic methods, Empirical Green's function method, Semi empirical methods, composite source model and hybrid methods.

The Empirical Green's function method has been introduced by Hartzell ${ }^{[1]}$. Later more development of the method has been made by Hadley and Helmberger $^{[2]}$, Irikura ${ }^{[3]}$. In this method the source parameters have been considered deterministically. Path effects and local site effects have been considered empirically, assuming that the motions recorded from aftershocks contained this information. By assuming $\omega^{2}$ spectral model for main shock and aftershocks, the aftershocks ground motion has been added to simulate the ground motion due to the main earthquake. In the methods proposed by Irikura ${ }^{[3]}$, the source physical parameters, such as strike, dip and rake angels and also the path effects, such as shear wave velocity, selected empirical green's functions, have been considered deterministically. In this study the Empirical green's function method was used for simulation of strong ground motion and also the probabilistic aspect of some of the mentioned parameters was added to the method.

Many parameters, used in strong ground motion simulation, have epistemic and aleatory uncertainties. The logic tree process is one of the methods for considering probabilistic aspect of these parameters. In this method each branch of logic tree corresponds with one of the alternatives for probabilistic parameters. The final probability can be calculated by multiplying all the probabilities for sub-branches of the main branch. In this study strike, dip and rake angles of seismic source and shear wave velocity of the medium were considered probabilistically.

GIS (Geographic Information System) tool is one of the most powerful devices for storing, modeling and analysis of geographic data. For this reason and more development capacity of this device, it is used for simulation of strong ground motion in this study and the proper program was developed in ArcGIS 9.0 software.

Corresponding Author: Amir Saedi Daryan, K.N. Toosi University of Technology, P.O. Box 15875-4416, Vali Asr St., Mirdamad Blvd., Tehran, Iran Tel: +982122749398 Fax: +982122749399 


\section{MATERIALS AND METHODS}

One of the methods for synthesizing strong ground motion is the Empirical Green's function method. In this method the ground motion time histories of small earthquakes (typically magnitude 2-3) are used for creating larger earthquakes ground motion time histories. In this method, it is assumed that the path and local site effect on strong ground motion time histories will be considered by using the modest magnitude time histories. In this method the geometry of seismic supply, source slip function, rupture pattern of seismic source and the proper empirical Green's function must be determined for simulation. The most suitable range of frequency for simulation by this method is between $0.2-1 \mathrm{~Hz}^{[3]}$.

According to Irikura formulations for simulation by Empirical Green's function method ${ }^{[3]}$, the source is considered as a rectangular plane. Next, by utilizing similarity laws between earthquakes, this plane will be divided into $\mathrm{N}$ sub-planes. Considering these subplanes as point sources, the Empirical Green's functions will be assigned to them. According to the time of reaching the rupture to the point on the fault and the time of reaching shear wave to the target point on the ground the time delay of adding Empirical Green's functions will be calculated. Adding Empirical Green's functions will result the main earthquake time history. The schematic consideration of seismic source in this method is shown in Fig. 1 and 2.

Two kinds of similarities between high and low magnitude earthquakes may be considered, source geometry similarity and source spectrum similarity. According to Kanamori and Anderson ${ }^{[4]}$, the similarity between physical properties of earthquakes is:

$$
\mathrm{L} / \mathrm{l}=\mathrm{W} / \mathrm{w}=\mathrm{T} / \mathrm{t}=\left(\mathrm{M}_{0} / \mathrm{m}_{0}\right)^{1 / 3}=\mathrm{D} / \mathrm{d}=\mathrm{N}
$$

In which $\mathrm{L}$ and 1 are seismic sources lengths, W and $\mathrm{w}$ are seismic sources widths, $\mathrm{T}$ and $\mathrm{t}$ are rise times, M0 and mo are moments and D and d are slip for main and element events respectively. The source spectrum similarity between main and element events will be formulated as follows ${ }^{[4]}$ :

$\mathrm{U}_{0} / \mathrm{u}_{0}=\mathrm{M}_{0} / \mathrm{m}_{0}=\mathrm{N}^{3}$

$\mathrm{A}_{0} / \mathrm{a}_{0}=\left(\mathrm{M}_{0} / \mathrm{m}_{0}\right)^{1 / 3}=\mathrm{N}$

These laws are based on the assumption of equal stress drops for main and element earthquakes. Assuming the ratio of stress drops of main and element

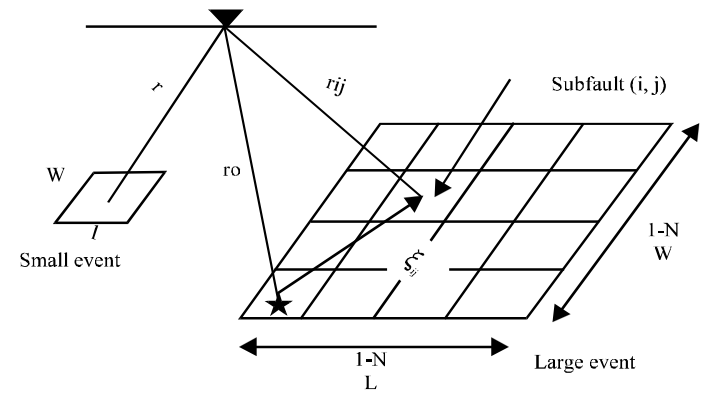

Fig. 1: Definition of Parameters used in simulation formulas

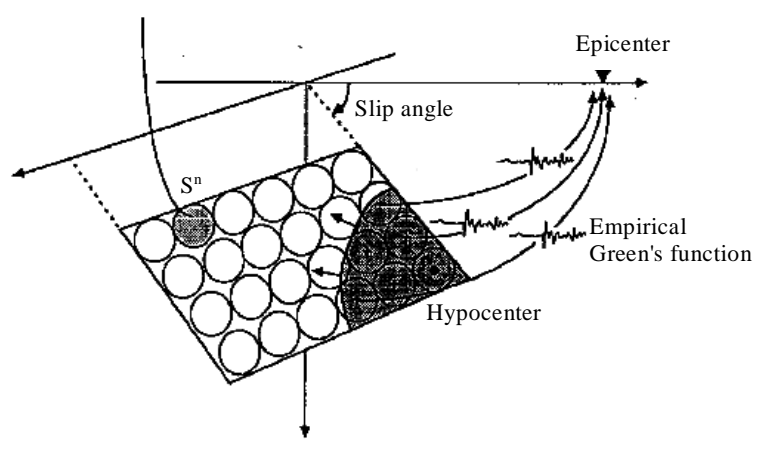

Fig. 2: Schematic illustration of EGF method

earthquakes equals to $\mathrm{C}$, the above formulations will be corrected as follows ${ }^{[4]}$ :

$\mathrm{U}_{0} / \mathrm{u}_{0}=\mathrm{M}_{0} / \mathrm{m}_{0}=\mathrm{CN}^{3}$

$\mathrm{A}_{0} / \mathrm{a}_{0}=\left(\mathrm{M}_{0} / \mathrm{m}_{0}\right)^{1 / 3}=\mathrm{CN}$

$\mathrm{L} / \mathrm{l}=\mathrm{W} / \mathrm{w}=\mathrm{T} / \mathrm{t}=\left(\mathrm{M}_{0} /\left(\mathrm{Cm}_{0}\right)\right)^{1 / 3}=\mathrm{N}$

$\mathrm{D} / \mathrm{d}=\mathrm{CN}$

According to these similarity laws below formulation obtained for simulation of ground motion time histories:

$A(t)=\sum_{i=1}^{N} \sum_{j=1}^{M} \frac{r}{r_{i j}} F(t) * a(t)$

In which $r$ is the hypocenter distance for element event, $r_{i j}$ is the hypocenter for sub-fault $i, j . F(t)$ is the filtering function for correction of slip velocity. $a(t)$ is the ground motion time history for the element earthquake and * means convolution. The proposed correction functions by Irikura $^{[3]}$ and Irikura et al. ${ }^{[5]}$ are presented in formulas (9) and (10) respectively. 
Am. J. Engg. \& Applied Sci., 2 (1):160-164, 2009
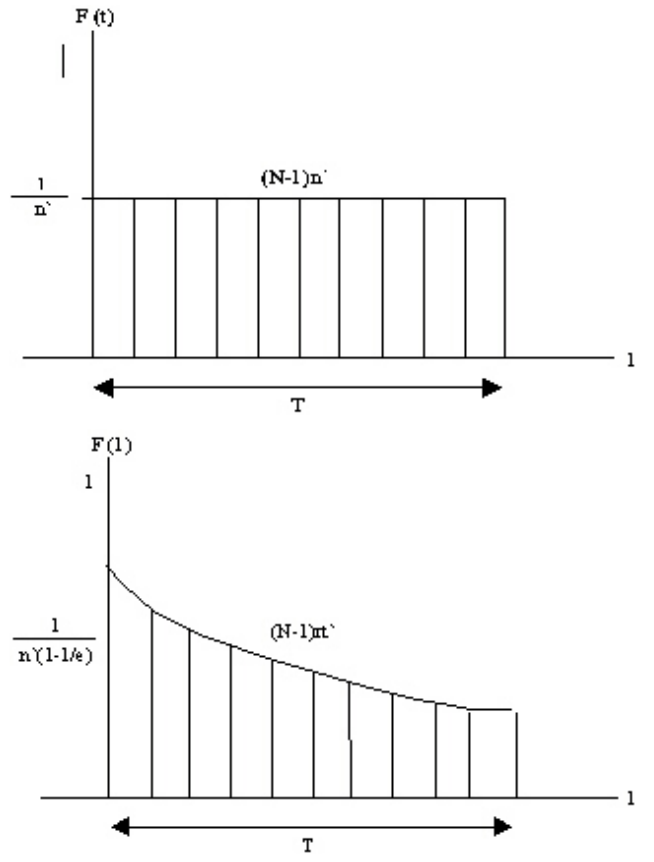

Fig. 3: Correction for different slip function between element and main earthquakes

Table 1: The bam main earthquake parameters

\begin{tabular}{llllllll}
\hline & \multicolumn{3}{l}{ Epicenter location } & & & \multicolumn{3}{c}{ PGA $\left(\mathrm{cm} \mathrm{sec}^{-2}\right)$} & \\
& - & & & \\
Source & longitude & latitude & Mw & Ms & L & V & T \\
\hline IIEES & 58.30 & 29.06 & & & & & \\
NEIC & 58.33 & 29.00 & 6.5 & 6.7 & 778.3 & 979.95 & 623.44 \\
IGTU & 58.40 & 29.21 & & & & & \\
\hline
\end{tabular}

Also the schematic views of these functions are demonstrated in Fig. 3:

$$
\begin{aligned}
\mathrm{F}(\mathrm{t})= & \delta\left(\mathrm{t}-\mathrm{t}_{\mathrm{ij}}\right)+\frac{1}{\mathrm{n}^{\prime}} \sum_{\mathrm{k}=1}^{(\mathrm{N}-1) \mathrm{n}^{\prime}}\left[\delta\left(\mathrm{t}-\mathrm{t}_{\mathrm{ij}}-\frac{(\mathrm{k}-1) \mathrm{T}}{(\mathrm{N}-1) \mathrm{n}^{\prime}}\right)\right] \\
\mathrm{F}(\mathrm{t})= & \delta\left(\mathrm{t}-\mathrm{t}_{\mathrm{ij}}\right)+\frac{1}{\mathrm{n}^{\prime}(1-1 / \mathrm{e})} \\
& \sum_{\mathrm{k}=1}^{(\mathrm{N}-1) \mathrm{n}^{\prime}}\left[\frac{1}{\left.\mathrm{e}^{\frac{(\mathrm{k}-1)}{(\mathrm{N}-1) \mathrm{n}^{\prime}}} \delta\left[\mathrm{t}-\mathrm{t}_{\mathrm{ij}}-\frac{(\mathrm{k}-1) \mathrm{T}}{(\mathrm{N}-1) \mathrm{n}^{\prime}}\right]\right]}\right.
\end{aligned}
$$

$t_{i j}$ is defined as follows:

$$
\mathrm{t}_{\mathrm{ij}}=\left(\frac{\mathrm{r}_{\mathrm{ij}}-\mathrm{r}_{0}}{\mathrm{~V}_{\mathrm{s}}}\right)+\frac{\xi_{\mathrm{ij}}}{\mathrm{V}_{\mathrm{r}}}
$$

In these formulas $r_{i j}$ is the distance between target point to $i, j$ element on the seismic source, $V_{s}$ is shear wave velocity, $\mathrm{V}_{\mathrm{r}}$ is rupture velocity, $\xi_{\mathrm{ij}}$ is the distance between rupture starting point to the $\mathrm{i}, \mathrm{j}$ sub-fault,
Table 2: Green functions characteristics

\begin{tabular}{llllllllll}
\hline & & \multicolumn{3}{c}{ Epicenter location } & & \multicolumn{3}{c}{ PGA $\left(\mathrm{cm} \mathrm{sec}^{-2}\right)$} \\
Source & - Name & Longitude & latitude & Mw & Ms & L & V & T \\
\hline IIEES & Green1 & 58.43 & 29.18 & 4.5 & - & 15.157 & 9.73 & 20 \\
IIEES & Green2 & 58.33 & 29 & 3.1 & - & 8.236 & 5.60 & 24 \\
\hline
\end{tabular}

Table 3: Bam fault parameters

\begin{tabular}{lllll}
\hline Length $(\mathrm{Km})$ & Width $(\mathrm{Km})$ & Strike & Dip & Rake \\
\hline 18 & 10 & 166 & 36 & 171 \\
\hline
\end{tabular}

Table 4: Filtering coefficients used in simulation Filtering coefficients

\begin{tabular}{lllll}
\hline FL & FH & FS & AP & AS \\
\hline 0.15 & 20 & 25 & 0.1 & 30 \\
\hline
\end{tabular}

$\mathrm{n}$ ` is an integer for avoiding unwanted periodicity in simulated time history. The main formula, which is used in this study for simulation is:

$$
\begin{aligned}
\mathrm{A}(\mathrm{x}, \mathrm{t})= & \sum_{\mathrm{i}=1}^{1} \sum_{\mathrm{j}=1}^{\mathrm{m}} \frac{\mathrm{F}_{\mathrm{ij}}^{\mathrm{s}}}{\mathrm{F}_{\mathrm{o}}^{\mathrm{s}}} \frac{\mathrm{r}_{\mathrm{o}}}{\mathrm{r}_{\mathrm{ij}}} \mathrm{a}\left(\mathrm{x}, \mathrm{t}-\mathrm{t}_{\mathrm{ij}}\right) \\
& +\sum_{\mathrm{i}=1}^{1} \sum_{\mathrm{j}=1}^{\mathrm{m}} \sum_{\mathrm{k}=1}^{(\mathrm{n}-1) \mathrm{n}^{\prime}} \frac{\mathrm{F}_{\mathrm{ij}}^{\mathrm{s}}}{\mathrm{F}_{\mathrm{o}}^{\mathrm{s}}} \frac{\mathrm{r}_{\mathrm{o}}}{\mathrm{r}_{\mathrm{ij}}} \frac{1}{\mathrm{n}^{\prime}} \mathrm{a}\left(\mathrm{x}, \mathrm{t}-\mathrm{t}_{\mathrm{ij}}-\frac{(\mathrm{k}-1) \tau}{\mathrm{n} \cdot \mathrm{n}^{\prime}}\right)
\end{aligned}
$$

In which $\mathrm{F}_{\mathrm{ij}}^{\mathrm{s}}$ and $\mathrm{F}_{0}{ }^{\mathrm{s}}$ are radiation pattern coefficients for element and main earthquakes respectively, $\tau$ is the rise time for main earthquake ${ }^{[3]}$. According to this formulation computer program was developed under GIS.

Data used for probabilistic ground motion simulation: The data of Bam 2003 earthquake is used for simulation. The earthquake was happened on December 26th in Bam. The main earthquake parameters are shown in Table $1^{[6]}$. Two after shocks were used as empirical Green's Functions for simulation. The green functions characteristics are shown in Table $2^{[7]}$. The Bam fault parameters are shown in Table $3^{[8]}$.

The shear wave velocity is considered $3.7 \mathrm{~km} \mathrm{sec}^{-1}$ and the rupture velocity is equal to 0.9 times the shear wave velocity ${ }^{[6]}$. Considered filtering parameters are shown in Table 4.

Element earthquakes and main event earthquake acceleration time histories are shown in Fig. $4^{[7]}$.

Probabilistic parameters: Shear wave velocity, seismic source geometry angles and empirical green function are considered probabilistically in this research. For shear wave velocity and seismic source geometry angles normal probability distribution is used. 

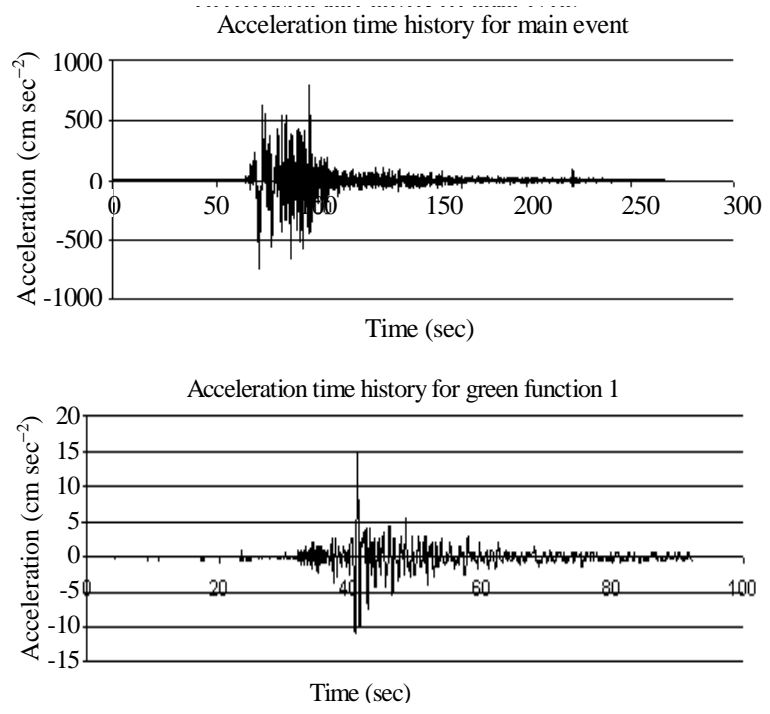

Fig. 4: Element earthquakes and main earthquake acceleration time histories

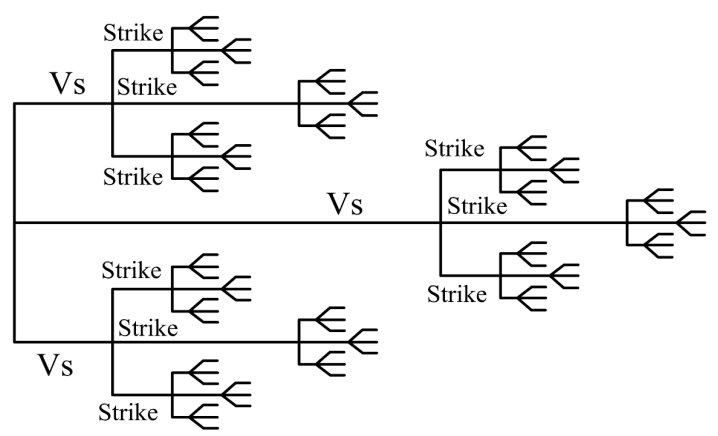

Fig. 5: Arrangement of logic tree method used for simulation

Table 5: Probabilities of different shear wave velocities

\begin{tabular}{ll}
\hline Shear wave velocity $\left(\mathrm{km} \mathrm{sec}^{-1}\right)$ & Probability \\
\hline 3.2 & 0.3054 \\
3.7 & 0.3892 \\
4.2 & 0.3054 \\
\hline
\end{tabular}

Table 6: Probabilities for different seismic source angles

\begin{tabular}{llll}
\hline Strike & Dip & Rake & Probability \\
\hline 161 & 31 & 166 & 0.31 \\
166 & 36 & 171 & 0.38 \\
171 & 41 & 176 & 0.31 \\
\hline
\end{tabular}

For selection of element event a coefficient based on the distance between the target function epicenter and element earthquake epicenter is assigned as the element function probability. The probability values for shear wave velocity based on normal probability distribution are shown in Table 5. In Table 5 the mean shear wave velocity is $3.7 \mathrm{~km} \mathrm{sec}^{-1}$ with standard deviation equals to $0.5 \mathrm{~km} \mathrm{sec}^{-19]}$. The probability table for geometrical seismic source angles is shown in Table 6. In Table 6, the estimated angle is considered as the mean value and the standard deviation of $5^{\circ}$ for each angle is considered ${ }^{[6]}$.

For element event selection, the empirical green function 1 probability value of 0.65 and for green function 2 probability value of 0.35 are considered. The arrangement of logic tree method is shown in Fig. 5. 162 simulations were performed totally.

\section{RESULTS}

Peak ground acceleration and frequency content of simulated ground motion time histories are the simulation results considered. For each of these parameters the probability distribution according to logic tree method is achieved. For PGA the probability density function according to all cases of simulation is shown in Fig. 6.

The target PGA was $778.3\left(\mathrm{~cm} \mathrm{sec}^{-2}\right)$. According to probabilistic simulation 46 percent of simulated PGA was more than the target PGA and the most probability obtained was for interval $800-900\left(\mathrm{~cm} \mathrm{sec}^{-2}\right)$ and this probability is 0.39 . The cumulative distribution function for PGA is shown in Fig. 7. This probability distribution may be used for seismic hazard or probability based seismic design of structures.

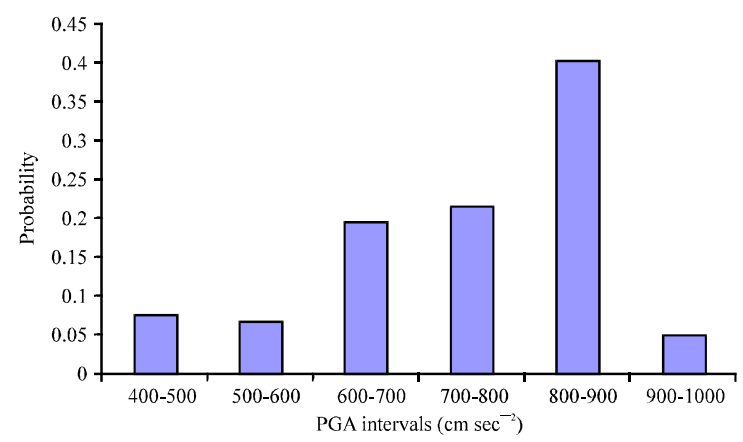

Fig. 6: Probability density function for simulated PGAs

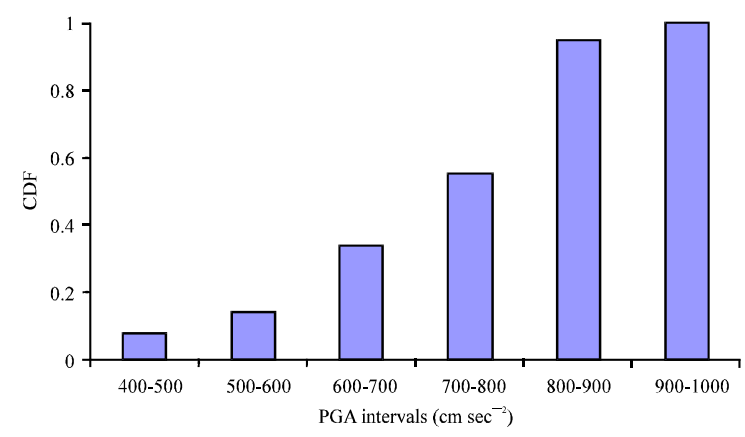

Fig. 7: Cumulative density function for simulated PGAs 


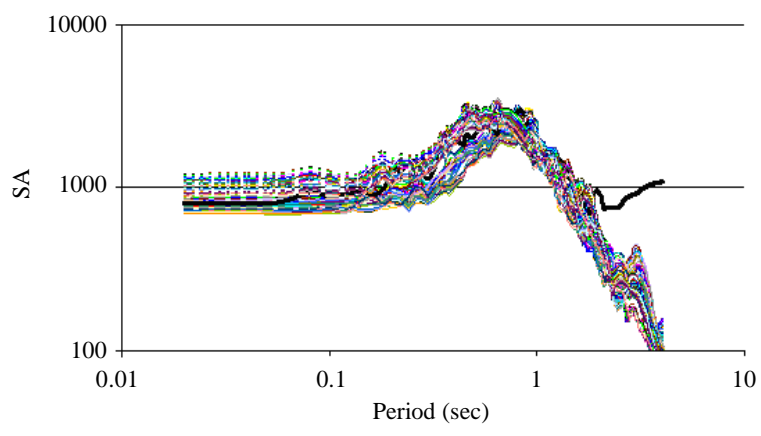

Fig. 8: Comparison of SA for simulated and target waveforms

\section{DISCUSSION}

The spectral acceleration for target and simulated time histories is compared in Fig. 8. In Fig. 8 the bold line shows the SA diagram for target earthquake time histories and other lines shows the SA for different cases of simulation results.

Future studies may be performed by using more tools of GIS for getting the geographical distribution of ground motion parameters due to the earthquake in the region. Also testing the attenuation relationships for regions by simulated ground motions, getting the source parameters and special source effects such as directivity effects on simulated ground motion time histories are other options for future studies.

\section{CONCLUSION}

In this research the Empirical Green's Function method was used to synthesize strong ground motion time histories. The probabilistic consideration for some of previous simulation processes parameters was inserted to the process. For implementing this method a computer program was developed in GIS. The 2003 Bam Earthquake strong ground motions were used for the simulation. Also for considering the probabilistic parameters the Logic Tree method was used. Probability distribution of peak ground acceleration and spectral acceleration were calculated and presented in this study. Future studies may be performed by using more tools of GIS for getting the geographical distribution of ground motion parameters due to the earthquake in the region.

\section{REFERENCES}

1. Murumatu, I. and H. Ohnuma, 1988. Synthesis of strong motions by using an aftershock record as the Green's function. Tectonophysics, 149: 275-288. DOI: 10.1016/0040-1951(88)90178-3.

2. Suzuki, S., K. Hada and K. Asano, 1998. Simulation of strong ground motions based on recorded accelerograms and the stochastic method. Soil Dynam. Earthquake Eng., 17: 551-556. DOI: 10.1016/S0267-7261(98)00015-3.

3. Xu Zhixin, 1988, On the stochastic modeling of earthquake strong ground motion. Nucl. Eng. Des., 110: 171-175. DOI: 10.1016/00295493(88)90019-2.

4. Ramazi, H. and H.S. Jigheh, 2006. The Bam (Iran) Earthquake of December 26, 2003: From an engineering and seismological point of view. J. Asian Earth Sci., 27: 576-584. DOI: 10.1016/j.jseaes.2005.05.009. 